\title{
Assessment of knowledge, attitude and practice of mothers/caregivers on infant and young child feeding in Assosa Woreda, Assosa Zone, Benshangul Gumuz Region, Western Ethiopia: a cross-sectional study
}

Dawit Getachew Assefa ${ }^{1,2^{*}}$ (D), Tigist Tekle Woldesenbet ${ }^{3}$, Wondowsen Molla ${ }^{4}$, Eden Dagnachew Zeleke ${ }^{1,5}$ and Timsel Girma Simie ${ }^{6}$

\begin{abstract}
Background: Through the health extension package, Ethiopia had practiced infant and young child feeding. However, infant and young child feeding (IYCF) practice has been poor. Hence, in this study, the knowledge, attitude, and practice of the mothers/caregivers on infant and young child feeding were assessed.

Methods: A cross-sectional study was carried out among 486 mothers/caregivers from Assosa Districts in the Assosa Zone of Benshangul Gumuz Region, Western Ethiopia. A semi-structured interviewer-administered questionnaire was used. To isolate independent predictors for good knowledge, good practice, and favorable attitude of the mothers/caregivers related to child feeding, multivariable logistic regression analyses were performed.
\end{abstract}

Results: Out of 486 study participants, 456 (93.8\%) of mothers had good knowledge, 432 (88.9\%) had a positive attitude, and 380 (78.2\%) mothers had good practice of IYCF practice recommendations. Furthermore, age of mothers, educational status of the mother, place of delivery, father's educational status, father's involvement \& support, previous knowledge about IYCF, discussion with their husband about IYCF, and ANC follows up were significantly associated with mother's knowledge on IYCF recommendation.

Conclusions: Overall mothers had good knowledge and a positive attitude about IYCF practices. To support IYCF practices, behavior change communications intervention strategies should be introduced in mothers to bridge the gap between knowledge and practices.

Keywords: Infant and young child feeding, Knowledge, Attitude, Practice

\footnotetext{
*Correspondence: dawit.getachew@aau.edu.et

${ }^{1}$ College of Health Sciences, Center for Innovative Drug Development and

Therapeutic Trials for Africa (CDT-Africa), Addis Ababa University, P.O. Box

9086, Addis Ababa, Ethiopia

${ }^{2}$ Department of Nursing, College of Health Science and Medicine, Dilla

University, Dilla, Ethiopia

Full list of author information is available at the end of the article
}

C C The Author(s). 2021 Open Access This article is licensed under a Creative Commons Attribution 4.0 International License, which permits use, sharing, adaptation, distribution and reproduction in any medium or format, as long as you give appropriate credit to the original author(s) and the source, provide a link to the Creative Commons licence, and indicate if changes were made. The images or other third party material in this article are included in the article's Creative Commons licence, unless indicated otherwise in a credit line to the material. If material is not included in the article's Creative Commons licence and your intended use is not permitted by statutory regulation or exceeds the permitted use, you will need to obtain permission directly from the copyright holder. To view a copy of this licence, visit http://creativecommons.org/licenses/by/4.0/. The Creative Commons Public Domain Dedication waiver (http://creativecommons.org/publicdomain/zero/1.0/) applies to the data made available in this article, unless otherwise stated in a credit line to the data. 


\section{Background}

Infant and young child feeding (IYCF) consists of initiation of breastfeeding within $1 \mathrm{~h}$ of birth, exclusive breastfeeding (EBF) for 6 months, a continuation of breastfeeding for up to 2 years and beyond the introduction of complementary foods, minimum dietary diversity, minimum meal frequency, minimum acceptable diet, and consumption of iron-rich or iron-fortified foods [13]. IYCF has a major role in determining the nutritional status of children, maximizing the growth rate of a child at early years of life $[2,4]$, and has great potential for reducing under-five malnutrition and thereby affecting child mortality rate. Also, to improve the child health and development outcomes in poorly resourced communities, improved IYCF practices are crucial [5]. Hence, factors, such as the knowledge, attitude, and practice (KAP) of mothers/caregivers on infant and young child feeding in this critical time are very important for child health, growth, and development $[4,6-8]$.

During optimal complementary feeding (CF) program the quantity and quality of food, frequency, and timeliness of feeding, food hygiene, and feeding during or after illness are highly considered [9]. Besides these facts, inadequate complementary feeding practice of 6 months to 2 years old children is a major problem [4]. In lowincome countries (LICs) improving the nutrition of infants and young children is a top priority for human development [5]. However, according to the 2020 world health organization's (WHO) report, in low- and middle-income countries under-nutrition was linked to $45 \%$ of deaths among children under 5 years of age. In the same year, 47 million children under 5 years of age are wasted, and 14.3 million are severely wasted and 144 million are stunted [3]. Inappropriate nutrition can also lead to childhood obesity which is an increasing public health problem in many countries [3].

Optimizing nutrition early in life including the 1000 days from conception to 24 months ensures the best possible start in life, with long-term benefits [10]. Especially, breastfeeding is one of the most effective ways to ensure child health and it could prevent $13 \%$ of deaths occurring in children less than 5 years of age globally, while appropriate complementary feeding practices would result in an additional $6 \%$ reduction in under-five mortality [11]. However, according to the current WHO report, nearly 2 out of 3 infants are not exclusively breastfed for the recommended 6 months a rate that has not improved in 2 decades [3].

In Sub-Saharan African regions, micronutrient deficiencies, poor quality of complementary foods, suboptimal infant feeding practices, and frequent infections have mainly contributed to the high mortality among infants and young children [12]. Since 2004 to improve feeding practice IYCF guideline was developed and implemented in Ethiopia. However, concerning all three IYCF practices (breastfeeding status, number of food groups, and times they were fed) the feeding practices of only $7 \%$ of children aged 6 to 24 months meet the minimum standard [13], and infant and young child feeding (IYCF) practice has been poor [14, 15]. Poor child feeding practices, inadequate quantities, and inadequate quality of complementary foods have a severe consequence on health and growth in children less than 2 years of age [16]. Therefore, this study was aimed to assess the knowledge, attitude, and practice of the mothers/caregivers on infant and young child feeding in Assosa Woreda, Assosa Zone, Benshangul Gumuz Region (BGR), Western Ethiopia.

\section{Specific objective}

To assess the maternal attitude towards the infant and young child feeding practices.

To assess the maternal practice regarding the infant and young child feeding practices.

To assess the maternal knowledge regarding the infant and child the feeding practices.

To identify the associated factors a of mother's knowledge on IYCF.

\section{Methods \\ Study setting and population}

the community-based cross-sectional study design was conducted in Assosa district, Ethiopia from May 20 -June 30, 2020. Assosa District is one of the seven administrative districts of Assosa zone, BGR, Ethiopia. The district is located $20 \mathrm{~km}$ away from Assosa, the capital city of BGR, and685 kilometers from Addis Ababa, Western Ethiopia. There are a total of 18,828 under-five children and 6,773 under 2 years of age infants [17]. The study populations were all mothers/caregivers whose children were $0-24$ months in selected districts. A multistage sampling method was employed. Nine subdistricts were selected from sub-district using a simple random sampling technique and from each sub-district participants were selected based on the proportion of children under the age of two in each kebele. Community Health Extension Workers (HEW) were provided the lists of all mothers who had a child under the age of two in each sub-district. A systematic random sampling method was employed to select study participants. When the household had more than one eligible child, one child was selected via a lottery method.

\section{Eligibility criteria \\ Inclusion criteria}

$\triangleright$ Mothers whose infant is under the age of two. 


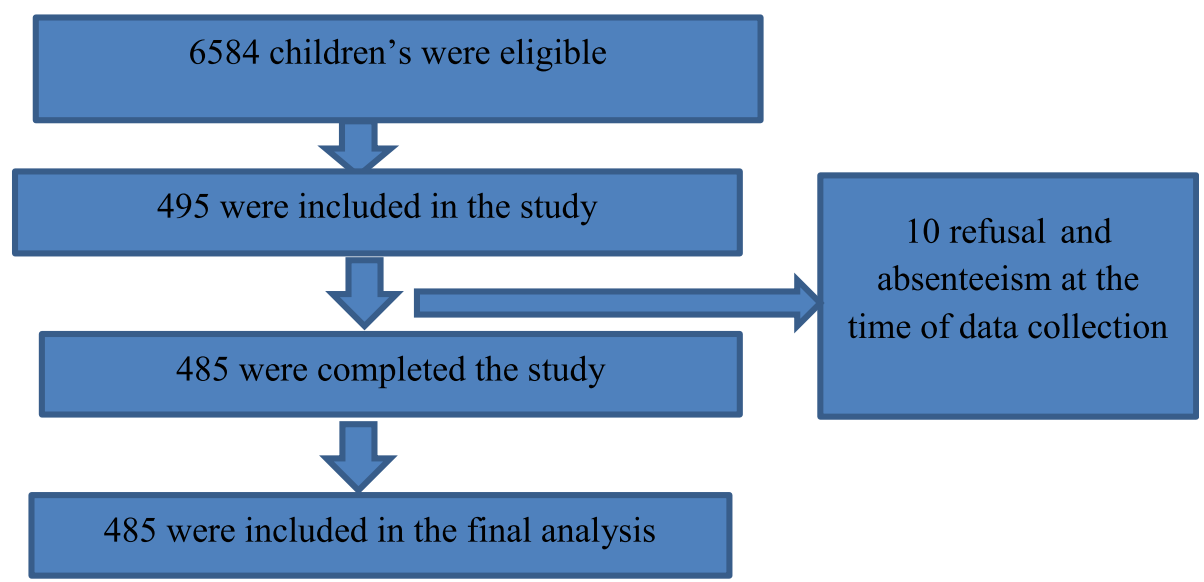

Fig. 1 Study flow diagram

$\triangleright$ Child families who were permanent residents in the study area.

$\triangleright$ The mother agrees and gives her consent to the study or others criteria.

\section{Exclusion criteria}

$\triangleright$ Children without their biological mother or actual caregivers.

$\triangleright$ Mothers with infants who are seriously ill and unable to communicate from any cause.

\section{Sampling technique}

A multistage sampling method was employed. Nine sub-districts were selected from 72 sub-districts using a simple random sampling technique and from each sub-district participants were selected based on the proportion of children under the age of two in each kebele. Community Health Extension Workers (HEW) were provided the lists of all mothers who had a child under the age of two in each sub-district. A systematic random sampling method was employed to select study participants. When the household had more than one eligible child, one child was selected via a lottery method.

\section{Sample size determination}

The sample size was determined using the formula of sample size determination for single population proportion $\mathrm{n}=(\mathrm{Za} / 2)^{2} P(1-p) / \mathrm{d}^{2}$. By the following assumptions: The level of confidence $(\alpha)$ is taken to be $95 \%$ $(\mathrm{Z} 1-\alpha / 2=1.96)$, and the margin of error $(\mathrm{d})$ is taken to be $5 \%$ [0.05]. The proportion (p) of the prevalence of practice on mother knowledge in IYCF was $28.7 \%$ (4). The calculated sample size was 495 mothers/ caregivers.

\section{Study variables}

Dependent variable

Mothers/caregiver knowledge, attitude, and practice on infant and young children feeding at the age of 0 to 24 months.

\section{Independent variables}

The independent variables were maternal socioeconomic and demographic factors, obstetrics and medical factors, maternal care utilization ANC, and breastfeeding practice.

\section{Data collection and data quality assurance}

Face to face interview was administered by a nurse after explaining the objectives when women were free and in a comfortable condition at their home or health facility. Data were collected using structured and pre-tested questioners. The questionnaires were first prepared in English, and translated into the local language (Amharic). The data collectors were given training on the process of data collection and during the data collection, consistent and accurate data were cheeked daily.

\section{Data management and analysis}

After checking the completeness and appropriateness, the data was coded and entered Epi Data 3.2, check for missing values and outliers, and was exported to SPSS 25 for data analysis. Descriptive frequencies and percentages were used to present the study results. First, a descriptive statistical analysis will be used, and mean, standard deviation (SD) was used to describe the sociodemographic characteristics and prevalence of knowledge, attitude, and practice on child feeding. Bivariate analysis was employed to identify the candidate variables for multivariable analysis at $p<0.025$ in binary analysis. Moreover, the proportion difference between the KAP by the socio-demographic background was analyzed by 
using Pearson's Chi-square tests after checking the assumptions. The multivariable results are reported as adjusted odds ratio (AOR) with $95 \% \mathrm{CI}$. The significance of the results was declared at $p<0.05$.

\section{Ethical consideration}

This proposal was submitted to Pharma College, school of graduate public health to be approved and obtaining a letter of clearance. An official letter of cooperation was also be given to the Assosa district health office and the Assosa zone health office. The Assosa district health office was asked for an official letter to get permission. Data collectors were trained how to handle confidentiality and privacy using the consent form attached to each questionnaire. Confidentiality was assured by excluding their name during the period of data collection.

\section{Results}

Socio-demographic characteristics of the respondents

The total response rate of the study was 486 (98.2\%). The reason for non-response was due to refusal and absenteeism at the time of data collection (Fig. 1).

The mean $( \pm \mathrm{SD})$ age of the participants was 29.5(5.4) years. The majorities were illiterate of which 232 $(47.7 \%)$ were unable to read and write, $412(84.8 \%)$ of them lives in rural areas, and $248(51.0 \%)$ of them were housewives (Table 1).

\section{Knowledge of respondents about IYCF practices}

Overall, $456(93.8 \%)$ mothers had good knowledge of IYCF practice recommendations. The majority, 408 $(84 \%)$ of participants realized that breast milk was the first feed that should be consumed by the child after birth within a $1 \mathrm{~h}$ of birth, and 416(85.6\%) women knew that exclusive breast-feeding means that an infant should receive only breast milk up to 6 months of life. Four hundred four (83.1\%) respondents identified the exact time of complementary feeding initiation. Among all respondents, the majority 442(90.9\%) knew mothers should take healthy food. Furthermore, four hundred forty-six (91.8\%) of respondents knew that breastfeeding could strengthen the bond between mother and child. More than three quarter $(76.1 \%)$ of respondents knew that breastfeeding helps to child and the majority $412(84.8 \%)$ of respondents knew that frequent breastfeeding is required when a child is sick (Table 2).

\section{The attitude of respondents towards IYCF practices}

Concerning attitude about IYCF, 410(84.4\%) participants agreed that breastfeeding should start immediately after delivery and $372(76.5 \%)$ also agreed that exclusive breastfeeding for the first 6 months is necessary. Approximately three quarter reported
Table 1 Maternal and child socio-demographic data in Assosa Zone, BGR, Western Ethiopia, 2020

\begin{tabular}{|c|c|c|}
\hline Variables & Frequency & Percent (\%) \\
\hline \multicolumn{3}{|l|}{ Age of mother } \\
\hline$<24$ & 82 & $16.9 \%$ \\
\hline $25-29$ & 178 & $36.6 \%$ \\
\hline$\geq 30$ & 226 & $46.5 \%$ \\
\hline \multicolumn{3}{|l|}{ Age of children (years) } \\
\hline $0-6$ months & 156 & $32.1 \%$ \\
\hline 6-12 months & 172 & $35.4 \%$ \\
\hline 12-18 months & 86 & $17.7 \%$ \\
\hline 19-24 months & 72 & $14.8 \%$ \\
\hline \multicolumn{3}{|l|}{ Sex } \\
\hline Male & 294 & $60.5 \%$ \\
\hline Female & 192 & $39.5 \%$ \\
\hline \multicolumn{3}{|l|}{ Place of residence } \\
\hline Rural & 412 & $84.8 \%$ \\
\hline Semi-urban & 74 & $15.2 \%$ \\
\hline \multicolumn{3}{|l|}{ Family size } \\
\hline$<3$ & 130 & $26.7 \%$ \\
\hline $4-6$ & 260 & $53.5 \%$ \\
\hline$>6$ & 96 & $19.8 \%$ \\
\hline \multicolumn{3}{|c|}{ Education status of the mother } \\
\hline Unable to read and write & 232 & $47.7 \%$ \\
\hline Able to read and write & 108 & $22.2 \%$ \\
\hline Primary education & 94 & $19.3 \%$ \\
\hline Secondary education & 32 & $6.6 \%$ \\
\hline College and above & 20 & $4.1 \%$ \\
\hline \multicolumn{3}{|c|}{ Education status of the father } \\
\hline Unable to read and write & 188 & $38.7 \%$ \\
\hline Able to read and write & 120 & $24.7 \%$ \\
\hline Primary education & 84 & $17.3 \%$ \\
\hline Secondary education & 54 & $11.1 \%$ \\
\hline College and above & 40 & $8.2 \%$ \\
\hline \multicolumn{3}{|c|}{ Occupational status of the mother } \\
\hline Housewife & 248 & $51 \%$ \\
\hline Farmer & 192 & $39.5 \%$ \\
\hline Merchant & 30 & $6.2 \%$ \\
\hline Daily laborer & 4 & $0.8 \%$ \\
\hline Gov't employee & 12 & $2.5 \%$ \\
\hline \multicolumn{3}{|l|}{ Parity } \\
\hline 1 & 416 & $85.6 \%$ \\
\hline 2 & 68 & $14.0 \%$ \\
\hline$\geq 3$ & 2 & $0.4 \%$ \\
\hline
\end{tabular}


Table 2 Knowledge of mother towards IYCF practices

\begin{tabular}{lll}
\hline Variable & Frequency & Percent (\%) \\
\hline Colostrum is important for baby & 394 & $81.1 \%$ \\
Yes & 44 & $9.1 \%$ \\
No & 48 & $9.9 \%$ \\
Don't know & 408 & $84 \%$ \\
A neonate should start breastfeeding within $\mathbf{1}$ h of birth & 42 & $8.6 \%$ \\
Yes & 36 & $7.4 \%$ \\
No & 36
\end{tabular}

An infant should exclusively breastfeed for the first 6 months

Yes 416

No $\quad 56$

$85.6 \%$

Don't know

An infant should start complementary food at 6 months

Yes

No

Don't know

Lactating mothers should take healthy food

Yes

No

Don't know

Did you wash your breast before breastfeeding

Yes

A snack should give to the child

Yes

No

Don't know

$\mathrm{BF}$ can strengthen the bond between mother and child Yes

No

Don't know

BF can prevent disease

Yes

Don't know

BF helps to child

Yes

Don't know
$83.1 \%$

$13.2 \%$

$3.7 \%$

$90.9 \%$

$1.2 \%$

$7.8 \%$

$51.0 \%$

$49.0 \%$

$81.1 \%$

$13.2 \%$

$5.8 \%$

$91.8 \%$

$7.4 \%$

$0.8 \%$

$54.7 \%$

$33.3 \%$

$11.9 \%$

$76.1 \%$

$19.8 \%$

$4.1 \%$

$51.9 \%$

$39.1 \%$

$9.1 \%$

BF more frequently when a child is sick 
Table 2 Knowledge of mother towards IYCF practices (Continued)

\begin{tabular}{|c|c|c|}
\hline Variable & Frequency & Percent (\%) \\
\hline Yes & 412 & $84.8 \%$ \\
\hline No & 74 & $15.2 \%$ \\
\hline Don't know & - & \\
\hline \multicolumn{3}{|l|}{ Who is usually feed a child } \\
\hline Mother & 436 & $89.7 \%$ \\
\hline Father & 4 & $0.8 \%$ \\
\hline Sibling & 44 & $9.1 \%$ \\
\hline Guardian & 2 & $0.4 \%$ \\
\hline \multicolumn{3}{|c|}{ Involvement and support of father on IYCF } \\
\hline Yes & 398 & $81.9 \%$ \\
\hline No & 60 & $12.3 \%$ \\
\hline Don't know & 28 & $5.8 \%$ \\
\hline \multicolumn{3}{|c|}{ Did you discuss with husband about child nutrition and feeding } \\
\hline Yes & 268 & $55.1 \%$ \\
\hline No & 218 & $44.9 \%$ \\
\hline \multicolumn{3}{|l|}{ Overall knowledge of IYCF } \\
\hline Good & 456 & $93.8 \%$ \\
\hline Poor & 30 & $6.2 \%$ \\
\hline \multicolumn{3}{|l|}{ Source of information } \\
\hline TV/ Radio & 12 & 2.5 \\
\hline Health facility & 270 & $55.6 \%$ \\
\hline On ANC/PNC follow up & 200 & $41.2 \%$ \\
\hline Relative/ Neighbor & 4 & $0.8 \%$ \\
\hline Social media (Facebook, ...) & - & \\
\hline other & - & \\
\hline
\end{tabular}

ANC Antenatal care, BF Breastfeeding, hrs hours, IYCF Infant and young children feeding, PNC Post natal care, TVTelevision

Table 3 Attitude of Respondents towards IYCF Practices

\begin{tabular}{|c|c|c|c|}
\hline Attitude question & Disagree & Not sure & Agree \\
\hline Breastfeeding should start immediately after delivery & $44(9.1 \%)$ & $32(6.6 \%)$ & $410(84.4 \%)$ \\
\hline Babies shouldn't be given anything except $B F \leq 6$ months & $88(18.1 \%)$ & $26(5.3 \%)$ & $372(76.5 \%)$ \\
\hline A child can be given butter, sugar, and water $\leq 6$ months & $276(56.8 \%)$ & $22(4.5 \%)$ & $188(38.7 \%)$ \\
\hline Complementary feeding should be started after 6 months & $36(7.4 \%)$ & $6(1.2 \%)$ & $444(91.4 \%)$ \\
\hline A formal meal is more convenient & $322(66.2 \%)$ & $28(17.3 \%)$ & $136(28 \%)$ \\
\hline Cow milk is more convenient & $370(76.2 \%)$ & $8(1.6 \%)$ & $108(22.2 \%)$ \\
\hline BF should continue up to 2 years & $22(4.5 \%)$ & $2(0.4 \%)$ & $462(95 \%)$ \\
\hline A child should be breastfeeding 10 and more than $10 / 24 \mathrm{hrs}$ & $18(3.7 \%)$ & $4(0.8 \%)$ & $464(95.5 \%)$ \\
\hline The child food to eat at one time should include VitA, and Fruit, etc... & $34(6.9 \%)$ & $14(2.9 \%)$ & 438(90.1\%) \\
\hline A snack should be given to the children between meal & $12(2.4 \%)$ & $30(0.8 \%)$ & $444(91.3 \%)$ \\
\hline Serving balanced foods prevent malnutrition disposal & $28(5.7 \%)$ & $16(3.3 \%)$ & $442(90.9 \%)$ \\
\hline Serving only starchy food prevent malnutrition & $274(56.4 \%)$ & $38(7.8 \%)$ & $174(35.8 \%)$ \\
\hline Malnutrition can be caused by disease & $76(15.6 \%)$ & $28(5.8 \%)$ & $382(78.6 \%)$ \\
\hline Serving indigenous fruit/vegetable can keep children healthy & $106(21.8 \%)$ & $24(4.9 \%)$ & $356(73.2 \%)$ \\
\hline
\end{tabular}


that babies shouldn't be given anything except breastfeeding until 6 months. Majorities 444(91.4\%) were agreed that complementary feeding should be started after 6 months (Table 3). Concerning the level of attitudes, more than half $(88.9 \%)$ of the participants had a positive attitude towards IYCF recommendations.

\section{IYCF practices}

A total of $406(83.5 \%)$ children were breastfed within an hour of their birth and the majority $370(76.1 \%)$ of children had more than ten frequencies of breastfeeding. In addition, three hundred eight $(87.2 \%)$ of children were exclusively breastfed for the first 6 months of life and nearly half $240(49.4 \%)$ children started with complementary feeds at 6 months. However, 334(68.7\%) children were complimentary food at least 3times/day. Overall, 380 (78.2\%) mothers had a good practice on IYCF (Table 4).

\section{Factors associated with mothers' knowledge}

In bivariate analysis, the data showed that there was no association between mothers' knowledge and the

Table 4 IYCF practice among respondent

\begin{tabular}{|c|c|c|}
\hline Variables & Frequency & Percent (\%) \\
\hline \multicolumn{3}{|c|}{ At what time you started BF after birth } \\
\hline Within $1 \mathrm{~h}$ & 406 & $83.5 \%$ \\
\hline After $1 \mathrm{~h}$ & 80 & $16.5 \%$ \\
\hline \multicolumn{3}{|c|}{ Frequency of BF in the last $24 \mathrm{~h}$} \\
\hline$<10$ times & 116 & $23.9 \%$ \\
\hline$\geq 10$ times & 370 & $76.1 \%$ \\
\hline \multicolumn{3}{|c|}{ Exclusive breastfeeding for the first 6 months } \\
\hline Yes & 308 & $63.4 \%$ \\
\hline No & 178 & $36.6 \%$ \\
\hline \multicolumn{3}{|c|}{ The time you started complementarily } \\
\hline$<6$ months & 172 & $35.4 \%$ \\
\hline At 6 months & 240 & $49.4 \%$ \\
\hline$>6$ months & 74 & $15.2 \%$ \\
\hline \multicolumn{3}{|c|}{ For how many years continued BF } \\
\hline$<2$ years & 88 & $18.1 \%$ \\
\hline$\geq 2$ years & 398 & $81.9 \%$ \\
\hline \multicolumn{3}{|c|}{ Minimum meal frequency of complementary food } \\
\hline Once & 30 & $6.2 \%$ \\
\hline Twice & 122 & $25.1 \%$ \\
\hline$\geq$ three times & 334 & $68.7 \%$ \\
\hline \multicolumn{3}{|c|}{ Overall status of IYCF practice } \\
\hline Good & 380 & $78.2 \%$ \\
\hline Poor & 106 & $21.8 \%$ \\
\hline
\end{tabular}

BF Breastfeeding, IYCF Infant and young children feeding variables analyzed, these variables include the place of the respondent, sex, marital status, religion, occupation, family size, etc.

In the binary logistic regression analysis age of mothers, educational status of the mother, place of delivery, educational status of the father's, father's involvement \& support, previous knowledge about IYCF, discussion with their husband about IYCF and ANC follow up were statistically associated with mothers knowledge on IYCF recommendation (Table 5).

After controlling the effect of other variables (confounders), the likelihood of a good knowledgeable mother was $71 \%$ times less likely for mothers age between $<24$ years old than mothers who were $\geq 30$ years old. Additionally, mother who had delivered in health institution were 4.47 time more knowledgeable than who had delivered at home.

More mothers who had ever heard information about IYCF were 3.66 times more knowledgeable than had not ever heard information about IYCF. Furthermore, mothers who had ANC follow-up were 12 times more knowledgeable than their counterparts who had no ANC follow-up.

\section{Discussion}

To our knowledge, this study was the first to be conducted in Assosa Zone, BGR, and Western Ethiopia. It was conducted to assess Knowledge, attitude, and practice towards IYCF, and associated factors among mothers' on IYCF.

Overall, $93.8 \%$ of mothers had good knowledge of IYCF practice recommendations. Mothers who have good knowledge of IYCF recommendations were more likely to have better feeding practices than mothers who have poor knowledge $[18,19]$. The finding that we get from this study was higher than the study findings in Bennatsemay woreda (45.7\%), and Nairobi city (49.5\%) $[20,21]$. On the other hand, this finding was lower than the study findings in Shebele Zone, in India, and Solapur city [22-25]. This disparity may be explained by the fact that most of the mothers in this study had no formal education on infant feeding [25], the time gap between studies, and the difference in the study settings; since the current study was done among mothers in with lower socio-economic status whereas the former studies included mothers in the Woreda with better socioeconomic characteristics.

The mother's general knowledge base was higher evidenced than an attitude about IYCF practices. Recent studies reported that the IYCF attitude of participants was limited $[5,14]$. On the contrary, other studies found a desirable attitude of mothers and fathers towards IYCF practices. However, even though the mothers perceived good knowledge, one-fourth of fathers influenced the 
Table 5 Factors associated with mother's knowledge regarding IYCF

\begin{tabular}{|c|c|c|c|c|c|}
\hline \multirow[t]{2}{*}{ Variables } & \multicolumn{2}{|c|}{ Mothers' knowledge of IYCF } & \multirow[t]{2}{*}{ COR(95 \%Cl) } & \multirow[t]{2}{*}{ AOR(95 \%Cl) } & \multirow[t]{2}{*}{ P.value } \\
\hline & Poor & Good & & & \\
\hline \multicolumn{6}{|l|}{ Age of mothers } \\
\hline$<24$ years & 8 & 74 & $0.8(0.33,1.92)$ & $0.29(0.1,0.85)^{*}$ & 0.024 \\
\hline 24-29 years & 4 & 174 & $3.76(1.25,11.3)$ & $1.92(0.58,6.34)$ & \\
\hline$\geq 30$ years & 18 & 208 & 1 & 1 & \\
\hline \multicolumn{6}{|c|}{ Educational status of the mother } \\
\hline Literate & 24 & 316 & $1.77(0.71,4.43)$ & & \\
\hline Illiterate & 6 & 140 & 1 & & \\
\hline \multicolumn{6}{|l|}{ Place of delivery } \\
\hline Home & 8 & 32 & 1 & 1 & 0.009 \\
\hline Health institution & 22 & 424 & $4.82(1.99,11.68)$ & $4.47(1.46,13.68)$ & \\
\hline \multicolumn{6}{|c|}{ Father educational status } \\
\hline Illiterate & 22 & 286 & 1 & & \\
\hline Literate & 8 & 170 & $1.64(0.71,3.75)$ & & \\
\hline \multicolumn{6}{|c|}{ Father involvement \&support } \\
\hline Yes & 22 & 376 & $1.71(0.74,3.98)$ & & \\
\hline No & 8 & 80 & 1 & & \\
\hline \multicolumn{6}{|c|}{ Did you ever heard information about IYCF } \\
\hline Yes & 24 & 436 & $5.45(2.0,14.8)$ & $3.66(1.16,11.61)$ & 0.027 \\
\hline No & 6 & 20 & 1 & 1 & \\
\hline \multicolumn{6}{|c|}{ Did you discuss with your husband about IYCF } \\
\hline Yes & 10 & 256 & $2.56(1.17,5.59)$ & & \\
\hline No & 20 & 200 & 1 & & \\
\hline \multicolumn{6}{|l|}{ ANC follow up } \\
\hline Yes & 2 & 278 & $21.9(5.14,92.9)$ & $12(4.84,25.1)$ & 0.001 \\
\hline No & 28 & 178 & 1 & & \\
\hline
\end{tabular}

ANC Antenatal care, AOR Adjusted odd ratio, Cls Confidence intervals, COR Crude odds ratio, IYCF Infant and young children feeding

earlier stopping of breastfeeding. This is due to a common belief in Papua New Guinea that whilst a woman is breastfeeding a couple should not resume sexual relations. To enhance good IYCF practices, the mothers/ caregivers need to have both good knowledge and attitude towards IYCF [23]. The current study was also supported a similar finding.

For the poor growth of children, poor practices can be one of the reasons. In a study conducted in West Bengal, India IYCF practice was higher and it was significantly related to the age and educational status of the mothers. One such study in Kerala reported that $84.1 \%$ of mothers exclusively breastfed their children [26]. It was reported that despite mothers having good knowledge about IYC, mothers' practice in feeding the child was poor [22-24]. Hence, despite their knowledge about IYCF hands-on training and practical exposure is the key to improve feeding practices.

It has been reported that $63.4 \%$ of mothers breastfed their child for the first 6 months, $65 \%$ of children were introduced to complementary feeds after the 6 months. Breast milk is the ideal food for infants. It is safe, clean, and contains antibodies that help protect against many common childhood illnesses $[3,16]$. In this study majority of mothers initiated breastfeeding the child within 1 $\mathrm{h}$ of birth which is higher than the previous study [27]. One former study was reported that the recommended duration for early breastfeeding recognized by $92 \%$ of the mothers, $96.9 \%$ knew about the duration for exclusive breastfeeding, although only $25 \%$ knew about the time to start complementary feeds [22]. In other previous studies, it was reported that $65.8 \%$ of infants were not initiated breastfeeding within $1 \mathrm{~h}$ of birth [2], $17 \%$ were breastfed exclusively [25], $74 \%$ were breastfed for 12 months and only $41 \%$ were initiated with complementary feeds at age of 6 months [28].

This study shows that the likelihood of a good knowledgeable mother was $71 \%$ times less likely for mothers age between $<24$ years old than mothers who were $\geq 30$ years old. A similar result was reported from a study finding 
in Nairobi city, Kenya [21]. Additionally, mother who had delivered in health institution were 4.47 time more knowledgeable than who had delivered at home.

More mothers who had ever heard information about IYCF were 3.66 times more knowledgeable than had not ever heard information about IYCF. Furthermore, mothers who had ANC follow up were 12 times more knowledgeable than their counterparts who had no ANC follow-up. This finding is in agreement with the study finding in northern Ethiopia and Arba Minch Zuria [29, 30]. Mothers who had ANC follow-up were more likely to be counseled by professionals on IYCF, which have a direct contribution to improve their knowledge level [31].

The study recommended revitalizing and expanding the baby-friendly hospital initiative and establishing breastfeeding intervention programs for protection, promotion, and support of breastfeeding. We also recommend for health workers to provide information on the involvement of the male partner in antenatal care is integrated into the public health system and education on infant and young child feeding recommendations should be strengthened during antenatal care visits and using mass media especially for mothers with lower educational status to fill up of this gap.

\section{Conclusions}

Overall, the mothers had good knowledge and a fair attitude about IYCF practices. Age of mothers, place of delivery, previous information about IYCF, and ANC follow-up were statistically associated with mother's knowledge of IYCF recommendations. Behavior change communications intervention strategies, which would support IYCF practices, should be introduced in mothers to bridge the gap between knowledge and practices.

\section{Strength and limitation of the study}

The questionnaire utilized for this study is based on the WHO IYCF Indicators parameters. This study was the first to be conducted in Asossa. However, the limitation of the study is that it was conducted among lactating mothers that opted for post-natal services, and hence, the findings of this study may not be representative of the situation of infant and young child feeding practices for the community at large.

\footnotetext{
Abbreviations

ANC: Antenatal Care; AOR: Adjusted Odd Ratio; BF: Breast Feeding; BGR: Benishangul Gumuz Region; CF: Complimentary feeding; Cls: Confidence Intervals; CSA: Central Statistical Authority; COR: Crude Odds Ratio; EBF: Exclusive Breast Feeding; EDHS: Ethiopian Demographic and Health Survey; hrs: Hour; HHs: Household; IHRERC: Institutional Health Research Ethical Review Committee; IYCF: Infant and Young Children Feeding; KAP: Knowledge, Attitude and Practice; LICs: Low- income countries; OR: Odds Ratio; PNC: Postnatal Care; SD: Standard Deviation; SPSS: Statistical Program for Social Science; TV: Television; UNICEF: United Nation Children's Fund; WHO: World Health Organization
}

\section{Acknowledgements}

The authors express their gratitude to Pharma College, the School of Graduate Studies, and the district administrators who provided us the necessary information in the study area.

\section{Authors' contributions}

DGA, TTW, WM, EDZ, and TGS design and conceived the study, developed the tool, coordinated data collection, and carried out the statistical analysis, and drafted the manuscript. All authors read and approved the final manuscript.

\section{Funding \\ This study did not receive any specific grant.}

Availability of data and materials

Data will be available upon request from the corresponding authors.

\section{Declarations}

Ethics approval and consent to participate

This study was approved by Pharma College, the school of graduate public health, and obtaining a letter of clearance. An official letter of cooperation was also being given to the Assosa district health office and the Assosa zone health office. Official letter to get permission obtained from the Assosa district health office. Privacy and confidentiality were maintained throughout the study period by excluding personal identifiers during data collection.

\section{Consent for publication}

Not applicable.

\section{Competing interests}

The authors declare that they have no competing interests.

\section{Author details}

${ }^{1}$ College of Health Sciences, Center for Innovative Drug Development and Therapeutic Trials for Africa (CDT-Africa), Addis Ababa University, P.O. Box 9086, Addis Ababa, Ethiopia. 'Department of Nursing, College of Health Science and Medicine, Dilla University, Dilla, Ethiopia. ${ }^{3}$ Department of Public Health, School of Graduate Studies, Pharma College, Hawassa, Ethiopia. ${ }^{4}$ Department of Midwifery, College of Health Science and Medicine, Dilla University, Dilla, Ethiopia. ${ }^{5}$ Department of Midwifery, College of Health Science, Bule-Hora University, Bule-Hora, Ethiopia. ${ }^{6}$ Department of Anesthesiology, College of Health Science and Medicine, Dilla University, Dilla, Ethiopia.

Received: 11 May 2021 Accepted: 9 September 2021 Published online: 26 September 2021

\section{References}

1. Sanghvi T, Martin L, Hajeebhoy N, Abrha TH, Abebe Y, Haque R, Tran HT, Roy S. Strengthening systems to support mothers in infant and young child feeding at scale. Food Nutr Bull. 2013;34(3 Suppl):156-68.

2. Das N, Chattopadhyay D, Chakraborty S, Dasgupta A. Infant and young child feeding perceptions and practices among mothers in a rural area of West Bengal, India. Ann Med Health Sci Res. 2013;3(3):370-5.

3. WHO. WHO fact sheet. 2020. Available at: https://www.hoint/news-room/fa ct-sheets/detail/malnutrition Accessed date: 26 Feb 2021.

4. World Health Organization. Global strategy for infant and young child feeding. 2003. Available at: https://www.hoint/nutrition/publications/infa ntfeeding/9241562218/en/ Accessed date: 2 May 2021.

5. Hackett KM, Mukta US, Jalal CS, Sellen DW. Knowledge, attitudes and perceptions on infant and young child nutrition and feeding among adolescent girls and young mothers in rural Bangladesh. Matern Child Nutr. 2015;11(2):173-89.

6. Dhami MV, Ogbo FA, Diallo TMO, Olusanya BO, Goson PC, Agho KE, on behalf of the Global Maternal and Child Health Research Collaboration (GloMACH). Infant and young child feeding practices among adolescent mothers and associated factors in India. Nutrients. 2021;13:2376. https//doi.org/10.3390/nu13072376.

7. World Health Organization USAID, AED, UCDAVIS IFPRI. Indicators for assessing infant and young child feeding practices. 2010. Available at: https://www.hoint/nutrition/publications/infantfeeding/9789241599757/en/ Accessed date: 2 May 2021. 
8. World Health Organization. Comprehensive implementation plan on maternal, infant, and young child nutrition. 2014. Available at: https://www. hoint/nutrition/publications/CIP_document/en/ Accessed date: 2 May 2021.

9. Jones AD, Ickes SB, Smith LE, Mbuya MNN, Chasekwa B, Heidkamp RA, Menon $P$, Zongrone AA, Stoltzfus RJ. World Health Organization infant and young child feeding indicators and their associations with child anthropometry: a synthesis of recent findings. Matern Child Nutr. 2014;10(1):1-17.

10. Khan GN, Ariff S, Khan U, Habib A, Umer M, Suhag Z, Hussain I, Bhatti Z, Ullah A, Turab A, et al. Determinants of infant and young child feeding practices by mothers in two rural districts of Sindh, Pakistan: a crosssectional survey. Int Breastfeed J. 2017;12:40.

11. Jones G, Steketee RW, Black RE, Bhutta ZA, Morris SS. How many child deaths can we prevent this year? Lancet. 2003;362(9377):65-71.

12. Lartey A. Maternal and child nutrition in Sub-Saharan Africa: challenges and interventions. Proc Nutr Soc. 2008:67(1):105-8.

13. Central Statistical Agency (CSA) [Ethiopia] and ICF. 2016. Ethiopia Demographic and Health Survey 2016. Addis Ababa, Ethiopia, and Rockville, Maryland: CSA and ICF.

14. Demilew YM, Tafere TE, Abitew DB. Infant and young child feeding practice among mothers with 0-24 months old children in Slum areas of Bahir Dar City, Ethiopia. Int Breastfeed J. 2017;12(1):26.

15. Asmare LDKM, Abebe AM, Abate BB, Tegegne KD. Prevalence and factors associated with child feeding practice among mothers of Woldia Town, Northeast Ethiopia. Nutr Diet Suppl. 2020;12:205-13. https:/doi.org/10.2147/NDS.S264282

16. Black RE, Allen LH, Bhutta ZA, Caulfield LE, de Onis M, Ezzati M, Mathers C, Rivera J. Maternal and child undernutrition: global and regional exposures and health consequences. Lancet. 2008;371(9608):243-60.

17. Central Statistical. Agency (CSA) E: Projection of Assosa district. 2020

18. Garg M, Hasan M, Kapur D: Infant and Young Child Feeding (IYCF) practices in Udupi district, Karnataka. 2015.

19. Nankumbi J, Muliira JK. Barriers to infant and child-feeding practices: a qualitative study of primary caregivers in rural Uganda. J Health Popul Nutr. 2015;33(1):106-16.

20. Tadesse A. Predictors of infant and young feeding practices among children 6-23 months old in Bennatsemayworeda, Ethiopia. J Nutr Health Food Eng. 2018;8(6):410-20. https://doi.org/10.15406/jnhfe.2018.08.00304

21. Kigaru DMD, Loechl C, Moleah T, Macharia-Mutie CW, Ndungu ZW. Nutrition knowledge, attitude, and practices among urban primary school children in Nairobi City, Kenya: a KAP study. BMC Nutr. 2015;1(1):44.

22. Guled RA, Mamat NM, Bakar WAMA, Assefa N, Balachew T. Knowledge, attitude, and practice of mothers/caregivers on infant and young child feeding in Shabelle Zone, Somali Region, Eastern Ethiopia: a cross-sectional study. 2016.

23. Jain S, Thapar RK, Gupta RK. Complete coverage and covering completely: breastfeeding and complementary feeding: Knowledge, attitude, and practices of mothers. Med J Armed Forces India. 2018;74(1):28-32.

24. Rajput RR, Haralkar SJ, Mangulikar SK. A study of knowledge and practice of breast feeding in urban slum area under urban health centre in Solapur city, Western Maharashtra. Int J Community Med Public Health. 2017:4:4692-6.

25. Kuzma J. Knowledge, attitude and practice related to infant feeding among women in rural Papua New Guinea: a descriptive, mixed-method study. Int Breastfeed J. 2013;8(1):16

26. Krishnendu M, Devaki G. Knowledge, Attitude and Practice Towards Breastfeeding Among Lactating Mothers in Rural Areas of Thrissur District of Kerala, India: A Cross-Sectional Study. Biomed Pharmacol J. 2017;10(2): 68390.

27. Deshpande MGD. Attitude and practices regarding infant and young child feeding among lactating mothers from rural areas of Nanded, Maharashtra. Biomed Pharmacol J. 2020;13(2). Available from: https://bitly/2M9Micv

28. Bentley A, Das S, Alcock G, Shah More N, Pantvaidya S, Osrin D. Malnutrition and infant and young child feeding in informal settlements in Mumbai, India: findings from a census. Food Sci Nutr. 2015;3(3):257-71.

29. Tamiru D: Maternal Knowledge of Optimal Breastfeeding Practices and Associated Factors in Rural Communities of Arba Minch Zuria. Int J Nutr Food Sci. 2013;122. https://doi.org/10.11648/jijnfs2013020315

30. Biks GA, Tariku A, Tessema GA. Effects of antenatal care and institutional delivery on exclusive breastfeeding practice in northwest Ethiopia: a nested case-control study. Int Breastfeed J. 2015;10(1):30.

31. Ahmad MO, Sughra U, Kalsoom U, Imran M, Hadi U. Effect of antenatal counseling on exclusive breastfeeding. J Ayub Med College Abbottabad. 2012;24(2):116-9.

\section{Publisher's Note}

Springer Nature remains neutral with regard to jurisdictional claims in published maps and institutional affiliations.
Ready to submit your research? Choose BMC and benefit from:

- fast, convenient online submission

- thorough peer review by experienced researchers in your field

- rapid publication on acceptance

- support for research data, including large and complex data types

- gold Open Access which fosters wider collaboration and increased citations

- maximum visibility for your research: over $100 \mathrm{M}$ website views per year

At BMC, research is always in progress.

Learn more biomedcentral.com/submissions 